\title{
Late melanoma metastasis to the urinary bladder mimicking bladder primary tumor
}

\author{
Michał Dybała', Wojciech M. Wysocki², 3, 4 \\ 'Department of Urology, $5^{\text {th }}$ Military Clinical Hospital in Krakow, Krakow, Poland \\ 2Department of General, Oncological and Vascular Surgery, $5^{\text {th }}$ Military Clinical Hospital in Krakow, Krakow, Poland \\ ${ }^{3}$ Chair of Surgery, Faculty of Medicine and Health Sciences, Andrzej Frycz Modrzewski Krakow University, Krakow, Poland \\ ${ }^{4}$ Scientific Editorial Office, Maria Sklodowska-Curie National Research Institute of Oncology, Warsaw, Poland
}

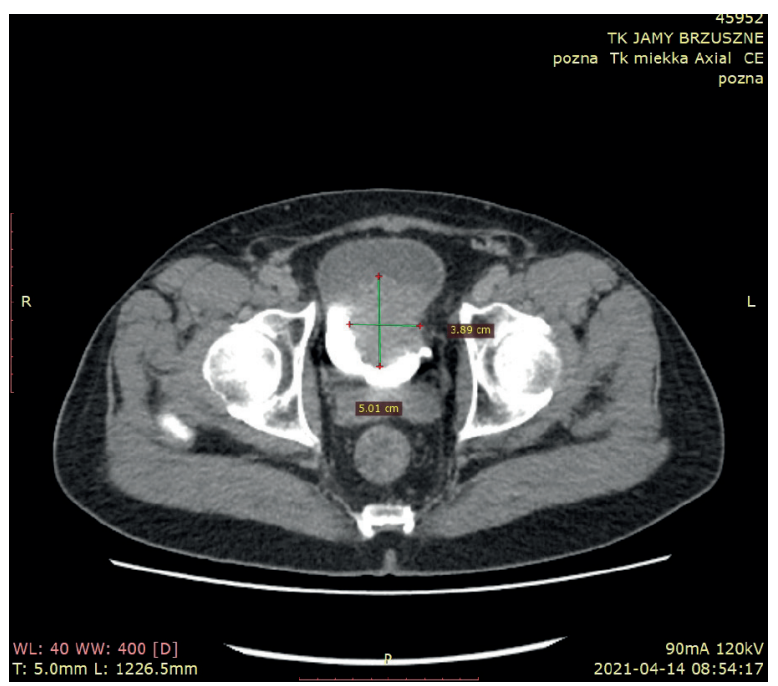

Figure 1. A CT scan of an extensively infiltrating $5 \mathrm{~cm}$ mass in the urinary bladder

A 60-year-old patient was diagnosed by CT with an extensively infiltrating $5 \mathrm{~cm}$ mass in the urinary bladder, in search of primary focus due to multiple brain metastases.

No known risk factors for urinary bladder carcinoma were present, however, in 2011 the patient underwent treatment for melanoma (Breslow $1.9 \mathrm{~mm}$ mitotic index 5/ $\mathrm{mm}^{2}$, SNB positive 2/3, completion axillary lymph node dissection 0/18, no adjuvant treatment).

The patient was referred for a transurethral bladder resection. On the left bladder wall a large mass was seen, partially ulcerated, with concomitant minor similar changes on the posterior wall and fundus. On histology a metastatic melanoma was diagnosed, with positive BRAF status. The patient was referred to brain irradiation for an unresectable brain foci and immunotherapy [1]. The urinary bladder is rare location

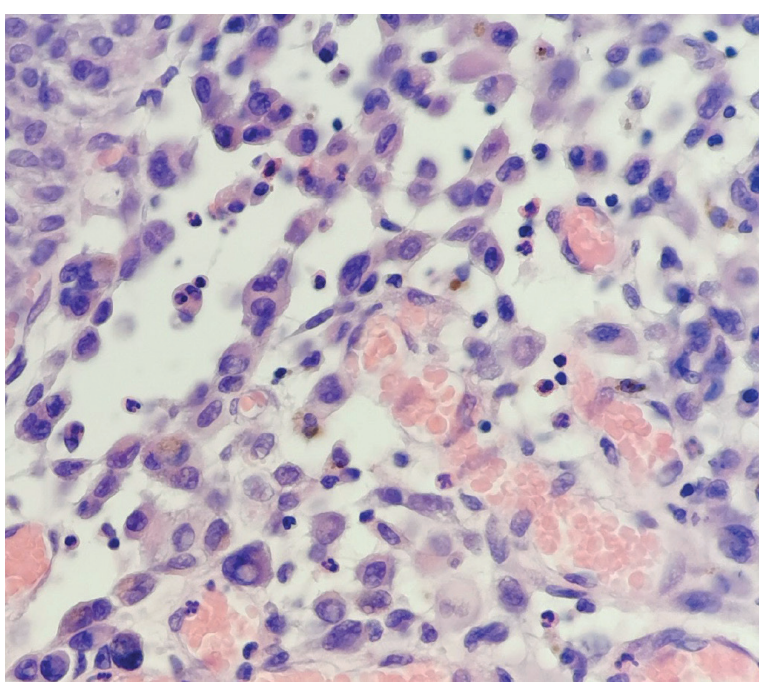

Figure 2. Microsopic image of melanoma submucosal infiltration in urinary bladder wall (HE 20x, courtesy of Dariusz Pabis MD)

for secondary seeds (up to 2-3\% of all bladder malignancies), and melanoma is extremely seldom among them (5\% of all bladder secondary malignancies) [2]. An upfront correct diagnosis is difficult from a clinical perspective (melanoma is a "great mimicker" of other diseases, like a primary bladder tumor in this case). Detailed history taking (including remote in-time medical details) and understating melanoma's ability to produce late-onset systematic recurrence might improve diagnostic specificity.

\section{References}

1. $\quad$ Rutkowski P, Kiprian D, Dudzisz-Śledź M, et al. Management of melanoma metastases in the brain. Nowotwory. Journal of Oncology. 2019; 69(3-4): 86-96, doi: 10.5603/njo.2019.0018.

2. Hamza A, Hwang MJ, Czerniak BA, et al. Secondary tumors of the bladder: A survival outcome study. Ann Diagn Pathol. 2020; 48: 151593, doi: 10.1016/j.anndiagpath.2020.151593, indexed in Pubmed: 32836180.

\section{How to cite:}

Dybała M, Wysocki WM. Late melanoma metastasis to the urinary bladder mimicking bladder primary tumor. NOWOTWORY J OnCol $2021 ; 71: 311$.

This article is available in open access under Creative Common Attribution-Non-Commercial-No Derivatives 4.0 International (CC BY-NC-ND 4.0) license, allowing to download articles and share them with others as long as they credit the authors and the publisher, but without permission to change them in any way or use them commercially. 